\title{
J.R.R. Tolkien: Pioneer of Worldbuilding
}

Ms. Rainysha Rawal

M.A.

Devi Ahilya Vishwavidyalaya

Indore, Madhya Pradesh, India

rainysharawal@gmail.com

Dr. Aparna Banik

Associate Professor

Head Department of English

Shri Cloth Market Girls School

Indore, Madhya Pradesh, India

aparnabanik96@gmail.com

\section{Abstract}

This paper explains after analysing critical aspects why J. R. R. Tolkien's efforts are the mere reason for generating huge interests among authors in Fantasy. Among the most prominent novels of 20th century, for considering excellence in any fantasy literature his works stood as a benchmark.

It also highlights about World Building. The greatest contribution belongs to Fantasy Literature is making of new worlds, providing new definition to fantasy and his esteem for different languages made him to use the Language as a constant to create the world from scratch. Tolkien may consider the creator of his own world - Middle-earth which acts as a Universe, it took around 60 years in the creation, has a deep meaning in everything which one can ever expect. He is a prolific artist and his created universe of own geography and history, 
flora and fauna, languages and cultures, physics and magic proved fine artist constructing the worlds.

Keywords: Worldbuilding, Fantasy, Hobbits, Languages, Secondary World, Sub-Creator 1. Introduction to J.R.R. Tolkien and his love for the languages

A famous English writer J.R.R. Tolkien, whose full name was John Ronald Reuel Tolkien was highbrow person who achieved popularity and became very famous by his books The Hobbit and creatively rich heroic fantasy The Lord of the Rings. He was born on January 3rd ,1892 lived the rich, unparalleled legacy for 81 years by bringing out new definition for fantasy through creating entire new world, his works were so popularised that later he became the Father of Modern World. His bequest was not even ended when he left the world on September 2nd, 1973 as his works were published even after death by his son. He lived in small family in South Africa. After the death of his father, being a protestant before, his mother changed the religion to Catholicism and in the meantime, Tolkien was learning reading and writing from his mother. This was the first influence ever which made his perceptions on Catholic view more transparent. His works were considered outstanding and was achieving mastery in Latin and Greek involving many arts of education ,he started becoming competent in Middle English, Old Norse, Welsh, Old English notably Gothic, and later Finnish.

After their mother's demise, two brothers chose to serve as a Catholic saint. Whereafter spending four years, Tolkien fell in love with Edith Bratt-an orphan girl who later became the source of his fictional character Lúthien Tinúviel. In adolescence, he used to teach literature with Old and Middle English specialization, at the Leeds University and Oxford University. In spite being involved in academic responsibilities, he produced few but prestigious publications, notably a standard edition of Sir Gawain and the Green Knight and a landmark lecture on Beowulf. 


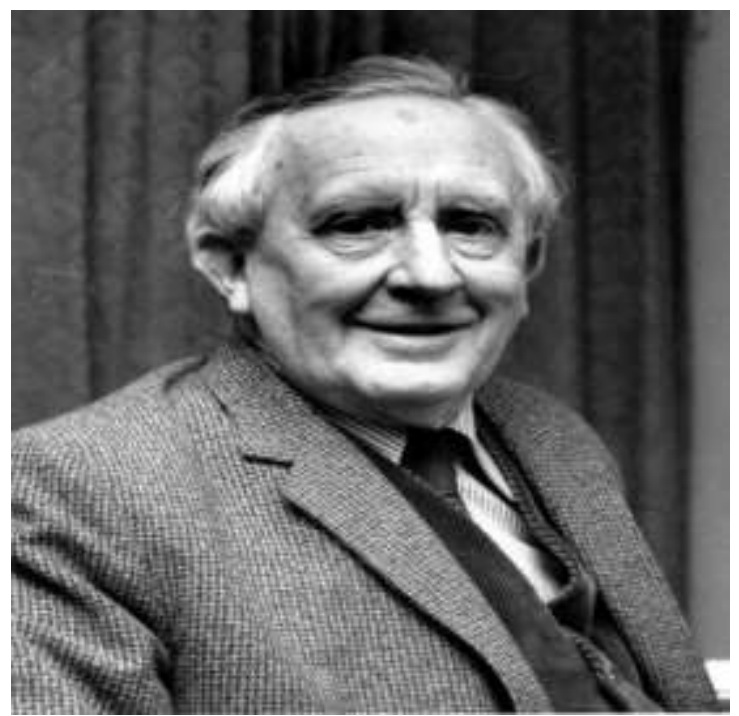

Fig 1: J.R.R Tolkien (1892-1973)

Tolkien used to remain occupied in making his own different types of languages, by elaborating fantasy tales, often evil and sorrowful, set his own creation purely for joy. Tolkien knew he needs some source of constant to create another world and it was the language which became the constant for creating, on basis of which entire culture can be build, flourish and grow with time. Language gives the characters their credibility, identity, origin and culture. This helped the world builders and especially Tolkien to create the world with more depth to bring cohesiveness. Language became the key component of his world that he built and hence the purpose of language being the progenitor was very important. Tolkien was so keen in learning languages that he even introduced the concept of parent language then that language related to real life and time split off into other languages that are related to each other but distinct from one another. Many times, this splitting happened thus creating multitude of languages.

The books written by Tolkien contain his legacy of unthinkable imaginations hence were loved by millions. It was Tolkien who laid out the formation using his innovations in 
world building from where other authors could take the motivation and create their own works.

Afterwards the most creative and popular his first novel - The Hobbit, begun around 1930 and got published in 1937, which was considered as an era-change time for fantasy works. It was about a provincial guy Bilbo Baggins blessed with comfort life, who was being guided by Wizard Gandalf and along with thirteen dwarves (smaller relative of Man) they went to claim their long-forgotten treasure stolen by a deadly dragon named Smaug.

In his classic fantasy novel The Hobbit, Tolkien explained the adventure of Dwarves Company by narrating the poem as:

The mountain smoked beneath the moon;

The dwarves, they heard the tramp of doom.

They fled their hall to dying fall

Beneath his feet, beneath the moon.

Far over the misty mountains grim

To dungeons deep and caverns dim

We must await, ere break of day,

To win the harps and gold from him!

(Tolkien 18-19)

On their way to the quest, they encountered many goblins, trolls, wargs, and other perils; but they were lucky to found Eagles, or Beorn who were helping them as friends. At the time of tunnel passage, Bilbo met Gollum who possessed the Golden Ring but by playing riddle game he took the Ring and escaped. Hobbit highlighted this quest of stolen treasury with well- developed emotional characters which made it to grab immense popularity that people were asking for its sequel. This Ring will begin the stories of the Lord of the Rings trilogy. 
Due to unending demands, Tolkien developed a sensational masterpiece- a modern way of depicting heroic epic, The Lord of the Rings. Hardly any component from The Hobbit depended, but that One Ring, must be thrown in the fire by anyone before Dark Lord, Sauron can get the Ring to rule the world (Middle Earth). Frodo with his fellowship sets out a journey to demolish the Ring which is in the trilogy. His trilogy, The Lord of the Rings is continuity to Silmarillion tales, which was the origin of new insight to the Fantasy World.

Tolkien delineated the destruction of ring in his masterpiece The Lord of the Rings as:

One Ring to rule them all, One Ring to find them,

One Ring to bring them all and in the darkness bind them.

(Tolkien 50)

2. Introduction to Worldbuilding and Sub Creation

World Building is an activity of creating a world which is unreal, fictional, full of imaginary creatures, unusual events and otherworldly places. By evolving an unreal domain mainly, it consists of physics, geography and ecology of the system and creates its own world which is based on fictional structure, the imagination of the writer, flora and fauna, maps, technologies created by different people, different backgrounds, different languages, and different culture.

The first ever fictional world was introduced in Phantastes, created by George MacDonald, further worlds were Wonderland by Lewis Carroll, Land of oz by L. Frank Baum, Neverland by J.M. Barie. From their influences J.R.R. TOLKEIN created unreal world, imaginary world, and secondary world and became the master of new worlds. In 1939, Tolkien published an essay on an act of creating worlds through the fairy tales, horror stories, love stories etc, but it was the Fairy Stories which became the most extensive statement. It was the Fairy Stories which led the beginning of the position equivalent to the God- creator and desecrator of our living. 
According to him, it is the imaginative and innovative thinking ability of human brain combining the parts of the Original World (reality) in another means is considered as subcreation. And when the arrangement of these combination of elements are done, it results and seems like shaping of new Secondary World which induces the readers to evoke Secondary Belief that sub-creation is the successful claim of Secondary world. And it was indeed the Fairy Stories- the revealing justification of Tolkien's methodology and work in famous novel. The Hobbit was a par excellence fairy-story, authors and readers found it as a high fantasy where the basic, fundamental and simple relations such as friendship and moral virtues were deeply exemplified and embedded in Bilbo Baggins. Ordinary man turning into hero was more eyes catching than ever any realist novelist made it before. It considered the very vital part of unreal world the unique creation of the tale or stories. Tolkien made his world "Middle Earth", he revealed his intentions through "Middle Earth" which was considered as the first fantasy novel truly justifying the reality of the secondary world. And acceptability of his own world was more comforting and real; he invented folklore, histories, languages and the maps and gave familiar touches to the Middle Earth so that it won't seem too strange and frightening. So, in this way, he carried the Unreal World shows the relationships, politics, love, realism, fantasy, wars in a very fantastic manner. This was the reason why he called as "The Father of Fantasy" because the only world he created was the "Middle Earth" but it took decades in making and creating of this world which has an equal depth and details to which other writers and people as well as children could ever imagine.

3. Elements of world building

The main fact and foremost feature is that Tolkien believed in ingredients value in making his own world. He took genres like High Fantasy, Low Fantasy, Dark Fantasy, Realism, Heroic fantasy which involves many key elements to bring Fictional World alive. Religion, Philosophy and Mythology - while building another world, almost all the authors 
started using the real-world inspiration. The word magic was not used explicitly however used as an 'elvish craft'. Magic was divided into soft (don't concern about rules and limitation) and hard magic (which concerns about the rules and limitations). In Politics it involves the dictatorship, monarchy, empire, democracy, theocracy, oligarchy, federation.

Another aspect of World Building was conflict, wars, culture, religion, customs, rituals, languages, history, achievements etc. As the real world has history of each and everything likewise in the fantastic world exists, the long history behind the stories. Another one is the technology which has the visionary ability for creating works beyond the imagination of the common people.

The very important fact of this world is the language and people with different appearances and strange creatures such as trolls, goblins, orcs, giants and other deadly beings. 4. Conclusion

Tolkien was a creator of fantasy world. His passion for learning and creating new languages made him to form his own world that only few authors can achieve.

He has outstanding insights into the world of fantasy and illusion that whatever works have been published by him had a universal appeal and that is why there are abundance of such types of books. His works were the beginning of breaking the barriers of old fantasy ideas.

The mere concept of Fairy Story turned out to be the beginning of the prestigious and most influential book ever which led the invention of world building, the image of Middle Earth which was a complex yet separated and independent for readers as well as for authors but the major part of attraction was the sub-creation. 


\section{Works Cited}

Tolkien, J.R.R. The Silmarillion. Boston, Houghyon Mifflin, 2001.

Tolkien, J.R.R. On Fairy stories( 1939 rev. 1964) in the Monsters and the Critics and Other essays. London, Harper Collins, 1997.

Tolkien, J.R.R. The Tolkien Reader. United States of America, Ballantine Books, 1966.

Fimi, Dimitra and Honegger, Thomas. Sucreating Arda: World building. Walking tree publisher, 2019.

Tolkien, J.R.R. The Hobbit. London, Harper Collins, 1991.

Tolkien, J.R.R. The Lord of the Rings. 2nd ed., vol. 1, Harper Collins, 2002 